Sarah Polkinghorne

Swinburne University of Technology, Melbourne, Australia

University of Alberta, Edmonton, Alberta, Canada

\title{
Coming to our senses: considerations for studying sensory information (Paper)
}

\begin{abstract}
Everyone uses information gathered through the senses to understand and navigate daily life. Despite this ubiquity, some types of sensory information have received little attention within library and information studies (LIS). This CAIS paper analyzes one sense as an example, the sense of smell, in order to identify cultural, linguistic, and methodological considerations for bringing it into greater focus within our discipline. This paper illustrates the complexities of studying sensory information, and argues that doing so will contribute to richer examinations of people's information practices.
\end{abstract}

\section{Résumé}

We perceive information through our senses on a daily basis. We use such information both consciously and unconsciously to navigate and understand our environment, the food and drink we consume, and our social and cultural circumstances. Despite this ubiquity, some types of sensory information, such as smells and tastes, have received little attention within library and information studies (LIS). This CAIS/ACSI paper analyzes one sense, the sense of smell, in order to identify considerations necessary for researchers to bring it into greater focus within our discipline. The paper illustrates the complexities of studying sensory information, and argues that doing so will contribute to richer examinations of people's information behaviours and practices.

LIS researchers are increasingly drawing attention to embodied information and knowledge (Cox, Griffin, \& Hartel, 2017; Keilty, 2016; Lloyd, 2009; Lloyd, 2010; Lueg, 2015; Olsson, 2016; Olsson \& Lloyd, 2017; Veinot, 2007). Researchers concerned with embodiment often discuss the senses while detailing how participants' bodies inform them about their surroundings. For example, Veinot reports on a hydroelectric vault inspector who is informed by "her physical ability to perceive temperature," which is important because "a vault that is hotter than it should be is one of the signs of potential overload" (2007, p. 167). Lloyd reveals how trainee firefighters gain "fire sense," the socially transmitted ability to use auditory, visual, and other information from the physical environment to understand and survive firefighting situations (2007, pp. 188- 
189). Olsson describes archaeologists' "striking" multi-sensory information practices and discovers that archeologists taste the artifacts they find at dig sites (2016, pp. 413-414).

Even in the context of this emerging interest in embodiment, close analyses of the senses are rare, such as Chen's work on aromatic archival records (2016). In the broader LIS literature, there is discussion of how books smell (e.g., Cave, 2012; Lieberman, 1997). There is also discussion of how people smell, particularly library patrons whose body odours may contravene library policies (e.g., Bardoff, 2015; Kelly, 2006). Beyond these two contexts, smell is not widely discussed. The potential to enrich our understanding of the sense of smell, and its role in people's information practices, is as plain as the nose on one's face.

Aromas are information. In the Smelly Old History book series, featuring Mouldy Mummies, Wartime Whiffs, and Tudor Odours, each book contains scratch and sniff panels to give readers an enhanced experience of the historical period described within (Dobson, 1998a; Dobson, 1998b; Dobson, Reid, \& Cottam, 1997). Meanwhile, chemists and engineers continue to pursue development of mechanized olfaction, also known as electronic nose technology (Patel, 2013). In medicine, anecdotal reports have suggested that dogs may be able sniff out cancer (Church \& Williams, 2001).

Aromas are also information retrieval triggers, powerful prompts for our episodic memories and affective associations (Saive, Royet, \& Plailly, 2014). In other words, any given smell is both information - airborne chemical compounds - and "memorial device" linking us to other information (Chen, 2016, p. 111).

To study the sense of smell in LIS, researchers must contend with a number of considerations. First, researchers must review the culturally situated nature of our own sensory experiences. Living in Western society in the $21^{\text {st }}$ century, this means that we perceive the senses hierarchically. Smell is at the bottom of the hierarchy. While powerful, and closely involved in how we interpret class, race, health, pleasure, and safety, smell is also elusive and ephemeral (Classen, 1994, p. 5). Since the Renaissance, the sense of sight has firmly occupied the top of the sensory hierarchy, entrenched with lens-based inventions such as telescopes and microscopes, along with the spread of print publications and other objects of longstanding interest to LIS researchers (Howes \& Classen, 2014, p. 2). Meanwhile, smell has been positioned as "a lower sense that promotes animal appetites rather than reasoned judgment and that blurs the basic western philosophic distinction between 'subjective' and 'objective"' (Sutton, 2010, p. 211). In a society that privileges notions of rationality and objectivity, smell has been "silenced' in modernity," assumed frivolous and unreliable for its ties to emotion, appetite, and domesticity (Classen, 1994, p. 4). As LIS researchers turn their attention to the senses, they must be reflective and transparent about possibly unconsidered sensory biases, such as implicit preferences for fixed, bounded, visible forms of information.

LIS researchers working in English also face lexical shortcomings, manifestations of the sensory hierarchy. We do not possess "a true olfactory vocabulary" (Classen, 1994, p. 109). We describe smells subjectively, and we do not have an array of abstract terms for 
them. For example, we describe the visual information we perceive from an apple in many ways: by colour, shape, texture, condition, emplacement, and so on. When we describe the olfactory information from that same piece of fruit, we describe whether it smells sweet or tart, ripe or rotten. We do not have the same breadth of descriptive options. Further, while we have words for abstract visual concepts such as "red," we interpret and describe aromas mainly in relation to their provenance: an apple smells like an apple. This is not necessarily because the sense of smell is less complex than the sense of sight, but rather because our language reflects sensory biases. For LIS researchers interested in the description and classification of aromas, it will be important to address these challenges. Information practices researchers must develop elicitation and analysis strategies that also account for linguistic challenges. For example, studies such as Pink's ethnographies of everyday practices, examining questions such as how people know when their laundry is clean, demonstrate that researchers can adapt familiar methods such as interviews to probe multi-sensory, sometimes tacit, information experiences (2005).

For the purposes of this CAIS paper, I examine the sense of smell as a discrete phenomenon, but of course it is not. We cannot study people's smell-related information experiences as separate from people's other sensory experiences. The senses of smell and taste, for example, are inextricably linked. An inability to smell greatly decreases the ability to taste (Provost, Bodwin, Kelly, Colabroy, \& Wallert, 2016, p. 85). People's sensory information experiences are also tied to their choices and actions. Evidence for this abounds, such as the well-established link between tasty smells (e.g., fresh pastries) and generous behaviour (e.g., informing a stranger that she's dropped her gloves outside the bakery) (Baron, 1997; Guéguen, 2012). For this reason, LIS researchers should avoid approaches that attempt to hive off the senses as a divorced object of analysis.

LIS researchers are attuned to "the red thread of information in the social texture of people's lives" (Bates, 1999, p. 1048). (The thread is red, but what does it smell like?) We can look closely at the thread and see a ply consisting of sensory information, which we encounter, seek, and use by interacting with our environments and social circles. It is timely for the senses to receive closer attention within LIS, because "people's knowledge of themselves, others, and the world they inhabit is inextricably linked to and shaped by their senses" (Sparkes, 2009, pp. 23-24). This paper, in outlining considerations around the sense of smell in LIS research, connects with this year's CAIS theme in two key ways. By incorporating research from psychology, history, and anthropology, this paper brings ideas from cognate disciplines to address concerns and concepts in LIS research. By offering a focused analysis of a single sense, this paper contributes to the development of an innovative future direction for our discipline.

\section{References}

Bardoff, C. (2015). Homelessness and the ethics of information access. The Serials Librarian, 69(3/4), 347-360. 
Bates, M. J. (1999). The invisible substrate of information science. Journal of the Association for Information Science and Technology, 50(12), 1043-1050.

Cave, R. (2002). The scent of libraries. Private Library, 5(3), 141-149.

Chen, A. (2016). Perfume and vinegar: Olfactory knowledge, remembrance, and recordkeeping. The American Archivist, 79(1), 103-120.

Church, J., \& Williams, H. (2001, September 15). Another sniffer dog for the clinic? The Lancet, 358(9285), 930. https://doi.org/10.1016/S0140-6736(01)06065-2

Classen, C. (1994). Aroma: The cultural history of smell. London: Routledge.

Cox, A., Griffin, B. L., \& Hartel, J. (2017). What every body knows: Embodied information in serious leisure. Journal of Documentation, 73(3). https://doi.org/10.1108/JD-06-2016-0073

Dobson, M. (1998a). Mouldy Mummies. Oxford: Oxford University Press.

Dobson, M. (1998b). Wartime Whiffs. Oxford: Oxford University Press.

Dobson, M., Reid, V., \& Cottam, M. (1997). Tudor Odours. Oxford: Oxford University Press.

Howes, D., \& Classen, C. (2014). Ways of sensing: Understanding the senses in society. London: Routledge.

Keilty, P. (2016). Embodied engagements with online pornography. The Information Society, 32(1), 64-73. https://doi.org/10.1080/01972243.2015.1107162

Kelly, J. (2006). Barefoot in Columbus: The legacy of Kreimer and the legality of public library access policies concerning appearance and hygiene. Public Libraries, 45(3), 42-49.

Lieberman, R. (1997). What is that smell? College and Undergraduate Libraries, 4(2), 51-53.

Lloyd, A. (2007). Learning to put out the red stuff: Becoming information literate through discursive practice. The Library Quarterly, 77(2), 181-198. https://doi.org/10.1086/517844

Lloyd, A. M. (2009). Informing practice: Information experiences of ambulance officers in training and on-road practice. Journal of Documentation, 65(3), 396-419. 
Lloyd, A. M. (2010). Corporeality and practice theory: Exploring emerging research agendas for information literacy. Information Research, 15(3). Retrieved from http://www.informationr.net/ir/15-3/colis7/colis704.html

Lueg, C. P. (2015). The missing link: Information behavior research and its estranged relationship with embodiment. Journal of the Association for Information Science and Technology, 66(12), 2704-2707. https://doi.org/10.1002/asi.23441

Olsson, M. (2016). Making sense of the past: The embodied information practices of field archaeologists. Journal of Information Science, 42(3), 410-419. https://doi.org/10.1177/0165551515621839

Olsson, M., \& Lloyd, A. M. (2017). Being in place: Embodied information practices. Information Research, 22(1). Retrieved from http://www.informationr.net/ir/221/colis/colis $1601 . h t m l$

Patel, H. K. (2013). The electronic nose: Artificial olfaction technology. New Delhi: Springer.

Pink, S. (2005). Dirty laundry: Everyday practice, sensory engagement and the constitution of identity. Social Anthropology, 13(3), 275-290. https://doi.org/10.1017/S0964028205001540

Provost, J. J., Bodwin, J., Kelly, B. S., Colabroy, K. L., \& Wallert, M. A. (2016). The science of cooking: Understanding the biology and chemistry behind food and cooking. Hoboken, NJ: Wiley.

Saive, A. L., Royet, J. P., \& Plailly, J. (2014). A review on the neural bases of episodic odor memory: From laboratory-based to autobiographical approaches. Frontiers in Behavioral Neuroscience, 8(240). https://doi.org/10.3389/fnbeh.2014.00240

Sparkes, A. C. (2009). Ethnography and the senses: Challenges and possibilities. Qualitative Research in Sport and Exercise, 1(1), 21-35. https://doi.org/10.1080/19398440802567923

Sutton, D. E. (2010). Food and the senses. Annual Review of Anthropology, 39(1), 209223. https://doi.org/10.1146/annurev.anthro.012809.104957

Veinot, T. C. (2007). “The Eyes of the Power Company”: Workplace information practices of a vault inspector. Library Quarterly, 77(2), 157-179. https://doi.org/10.1086/517842 